\title{
Prevalence and severity of asthma, rhinitis, and eczema in Singapore schoolchildren
}

\author{
D Y T Goh, F T Chew, S C Quek, B W Lee
}

\begin{abstract}
This study was part of an international effort to evaluate the epidemiology of asthma and allergic diseases around the world. The aim was to assess the prevalence and severity of these disorders in Singapore schoolchildren. The international study of asthma and allergies in childhood (ISAAC) written questionnaire was administered to 6238 schoolchildren. The respondents were parents of a 6-7 year cohort $(n=2030)$, and schoolchildren aged 12-15 years $(n=4208)$. The overall cumulative and 12 month prevalence of wheezing were $22 \%$ and $12 \%$, respectively. The prevalence of doctor diagnosed asthma was $20 \%$. Rhinitis was reported by $44 \%$ and chronic rashes by $12 \%$. Multiple logistic regression analysis showed that a higher prevalence of wheezing and rhinitis was associated with males, and subjects of higher socioeconomic status (based on type of housing and total family income). More severe asthma related symptoms were present in Malays and Indians than in the Chinese. Allergic disorders are common in Singapore and prevalence is comparable to some populations in the West. Demographic and socioeconomic factors appear to influence the prevalence and severity of these disorders.

(Arch Dis Child 1996; 74: 131-135)
\end{abstract}

Keywords: asthma, rhinitis, eczema, prevalence, severity.

The prevalence and severity of asthma is rising in many developed countries. ${ }^{1-3}$ The economic impact is staggering, with treatment costs in 1990 amounting to US $\$ 6.4$ billion of the US health bill, ${ }^{4}$ and about one billion pounds sterling in the United Kingdom at the same period. ${ }^{5}$ Eczema and rhinitis add substantially to this burden. Furthermore, there is the social cost with significant loss of school and work days.

Although it is known that the principal aetiological factor in asthma is atopy, ${ }^{6}$ the factors responsible for this observed increase are uncertain. There has been speculation that changes in lifestyle and urbanisation in industrialised countries may be partly responsible. ${ }^{7}$ This stems from the observation that the prevalence of asthma and allergic diseases appears to be lower in the Asian Pacific countries than in the West. ${ }^{9-12}$ However, the prevalence of childhood asthma in Singapore is increasing similarly, with cumulative asthma prevalence in schoolchildren rising from $5.5 \%$ to $14.7 \%$ between 1969 and $1987 .{ }^{1314}$ Some of this increase may be explained by differences in survey methods and an increased awareness of asthma diagnosis.

It is therefore important that epidemiological surveys on asthma are standardised to enable international and temporal comparisons. Moreover, international studies of asthma prevalence and severity could provide insights into the risk factors responsible for this rising asthma burden. To this end, an international childhood asthma prevalence study, the international study of asthma and allergies in children (ISAAC) was formed in $1992 .{ }^{15}$ In phase 1 of this ISAAC study, standardised written and video questionnaires were developed.

We have analysed the results of the ISAAC phase 1 written questionnaire survey of schoolchildren in Singapore. The population consists of Chinese $(75 \%)$, Malays $(15 \%)$, and Indians $(10 \%)$, so racial differences in the prevalence and severity of asthma, rhinitis, and eczema were evaluated. We attempted to compare our results with those from other studies using the same ISAAC protocol. ${ }^{16} 17$

\section{Methods}

QUESTIONNAIRES

The ISAAC written questionnaire for asthma was identical to those used previously ${ }^{16}$ (appendix). It concentrated on past and current wheezing episodes, wheezing frequency, sleep disturbance and speech limitation during attacks, exercise induced wheezing, persistent cough unrelated to respiratory infections, and a doctor's diagnosis of asthma. In addition, ISAAC core questions were included regarding the presence and severity of rhinitis and eczema (appendix). We assessed socioeconomic status by asking respondents for total family income and type of residence (public housing, condominium, or landed houses). The total family monthly income was categorised as $<S \$ 1000$, $S \$ 1000-1999, S \$ 2000-3999$, and $>S \$ 4000$, corresponding to the bottom 16th centile, bottom 16th-43rd centile, top 24th-57th centile, and top 24th centile, respectively, according to the Singapore population census in $1990 .{ }^{18}$ The response rate for family income was only $47 \%$, as most of the $12-15$ year olds who completed the questionnaire were unable to provide the information.

\section{DATA COLLECTION AND ANALYSIS}

We studied two age groups of schoolchildren (6-7 years, and 12-15 years). Thirty schools from all parts of Singapore were randomly selected, of which 21 consented to participate. The parents of the 6-7 year olds were the 
Table 1 Demographic profile and socioeconomic categories of study population; values are number (\%)

\begin{tabular}{|c|c|c|}
\hline \multirow[b]{2}{*}{ Variables } & \multicolumn{2}{|l|}{ Age groups } \\
\hline & 6-7 Years & $12-15$ Years \\
\hline $\begin{array}{l}\text { Sex } \\
\text { Male } \\
\text { Female } \\
\text { Not stated }\end{array}$ & $\begin{array}{c}1065(52) \\
947(47) \\
18(1)\end{array}$ & $\begin{array}{c}2335(55) \\
1866(44) \\
7(1)\end{array}$ \\
\hline $\begin{array}{l}\text { Racial groups } \\
\text { Chinese } \\
\text { Malay } \\
\text { Indian } \\
\text { Not stated }\end{array}$ & $\begin{array}{c}1722(85) \\
185(9) \\
68(3) \\
55(3)\end{array}$ & $\begin{array}{l}3282(78) \\
605(14) \\
215(5) \\
106(3)\end{array}$ \\
\hline $\begin{array}{l}\text { Type of housing } \\
\text { Public housing } \\
\text { Private condominium } \\
\text { Landed house } \\
\text { Not stated }\end{array}$ & $\begin{array}{r}1239(61) \\
276(14) \\
435(21) \\
80(4)\end{array}$ & $\begin{array}{c}3411(81) \\
319(8) \\
380(9) \\
98(2)\end{array}$ \\
\hline $\begin{array}{l}\text { Family income (S\$/month) } \\
\text { Less than } 1000 \\
\text { Above or equal } 1000 \text { and less than } \\
2000 \\
\text { Above or equal } 2000 \text { and less than } \\
\quad 4000 \\
\text { Above or equal } 4000 \\
\text { Not stated }\end{array}$ & $\begin{array}{l}130(6) \\
403(20) \\
\\
485(24) \\
760(37) \\
252(13)\end{array}$ & $\begin{array}{c}119(3) \\
\\
387(9) \\
\\
393(9) \\
214(5) \\
3095(74)\end{array}$ \\
\hline Total studied & 2030 & 4208 \\
\hline
\end{tabular}

respondents, while the $12-15$ year olds self completed the questionnaire. The survey was conducted in English, only a small number of non-English speaking parents required Mandarin (4.7\%) and Malay $(0 \cdot 3 \%)$ translations. This survey was carried out between the months of February and November 1994.

Data were analysed using the PROC FREQ and PROC LOGISTIC procedures of the statistical package SAS (version 6.08) for personal computers.

\section{Results}

There were 6238 responses, a rate of approximately $90 \%$. The demographic profile and socioeconomic categories of respondents are shown in table 1 . As a result of a mistake made in the initial part of the survey, 1331 6-7 year old respondents did not receive the core questions on eczema. Responses that were excluded from analysis included 69 with invalid $(n=17)$ or missing $(n=46)$ age, and those with inconsistent answers to stem questions on asthma $(n=218)$, rhinitis $(n=152)$, and eczema $(n=104)$. As a result, the number of valid responses for asthma, rhinitis and eczema were 6020,6086 , and 4803, respectively, as shown in table 2 .

PREVALENCE

The overall cumulative and current prevalences of self reported asthma, rhinitis and eczema, and their symptoms, are summarised in table 2. Reported symptoms of rhinitis had the highest cumulative prevalence (2710/6086, $44.5 \%$ ), followed by asthma (ever had wheezing, wheezing with exercise, or persistent cough) $(1856 / 6020,30.8 \%)$, and eczema $(578 / 4803,12.0 \%)$. The data were also divided by age group, sex, ethnic group, and socioeconomic status (type of housing and family income) (table 2). Reported symptoms of wheezing were observed to be higher in the 6-7 year age group, males, and higher socioeconomic groups. Statistical comparisons of these differences were made using multiple logistic regression (see below).

Although persistent rhinitis was the most commonly reported atopic symptom, the frequency with which these respondents reported hayfever was extremely low $(275 / 6086,4 \cdot 5 \%)$ (table 2) and $54.5 \%$ were not aware of this diagnosis. Moreover, 45/275 (16.4\%) reported having hayfever without having symptoms of rhinitis, suggesting a lack of understanding of the condition in our population. This assumption was consistent with the observed lack of seasonal variation in reported rhinitis symptoms. More than half (1170/2258, $52.3 \%$ ) of those currently having symptoms reported having them year round. In addition, analysis of the monthly frequency of reported symptoms showed little variation from month to month (range between 54.5 and $60 \cdot 8 \%$ ).

Table 2 Self reported prevalence (\%) of asthma, rhinitis and eczema and their related symptoms - written questionnaire

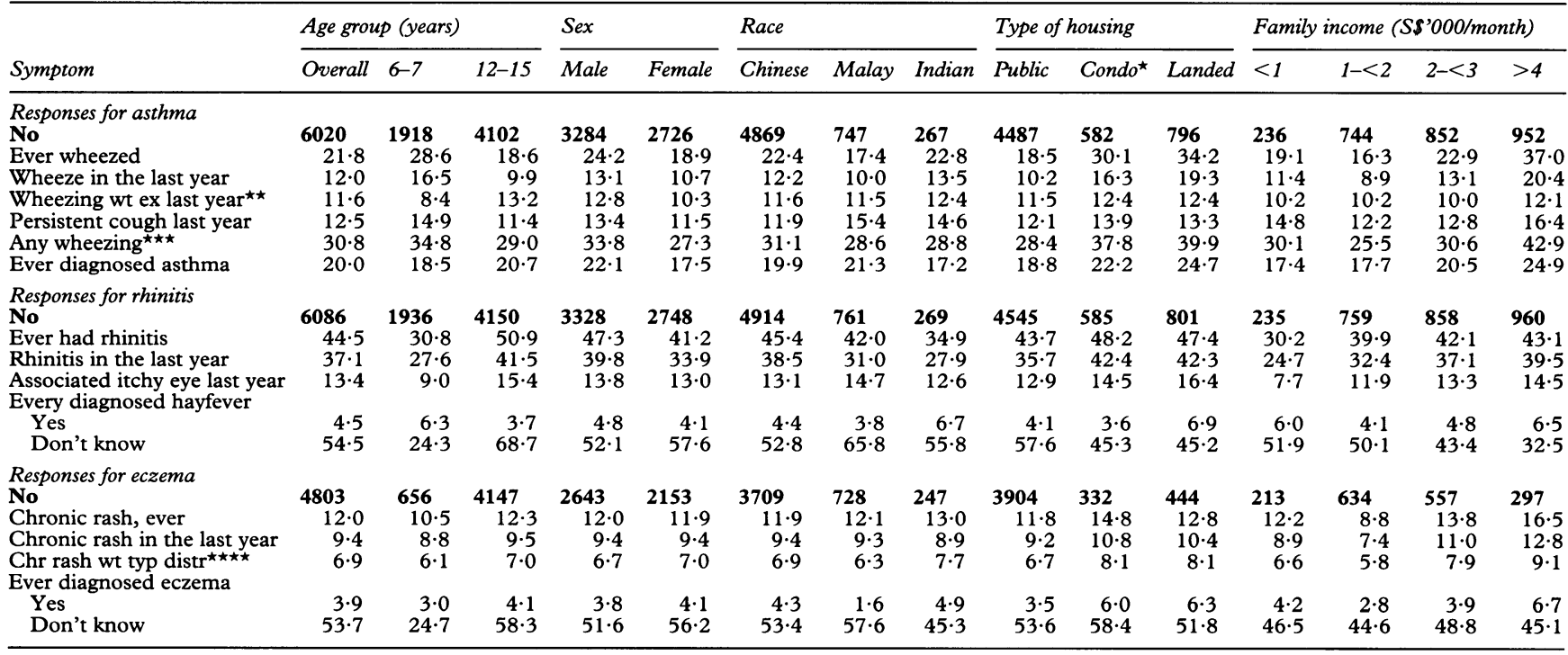

${ }^{\star}$ Condo $=$ condominium; ${ }^{\star \star} w \mathrm{wt}$ ex $=$ with exercise; ${ }^{\star \star \star}$ any wheezing $=$ ever wheezed, wheeze with exercise or persistent cough;

${ }^{\star}$ Condo $=$ condominium; ${ }^{\star \star}$ wt ex $=$ with exercise; ${ }^{\star \star \star \star}$ any wheezing
(n) 
Table 3 Prevalence (\%) of reported symptoms indicating severity of asthma, rhinitis, and eczema

\begin{tabular}{|c|c|c|c|c|c|c|c|c|c|c|c|c|c|c|c|}
\hline \multirow[b]{2}{*}{ Symptom } & \multirow[b]{2}{*}{ Overall } & \multicolumn{2}{|c|}{ Age group (years) } & \multicolumn{2}{|l|}{ Sex } & \multicolumn{3}{|l|}{ Race } & \multicolumn{3}{|c|}{ Type of housing } & \multicolumn{4}{|c|}{ Family income (S\$'000/month) } \\
\hline & & $6-7$ & $12-15$ & Male & Female & Chinese & Malay & Indian & Public & Condo $o^{\star}$ & Landed & $<1$ & $1-<2$ & $2-<3$ & $>4$ \\
\hline \multirow{6}{*}{$\begin{array}{l}\text { Wheeze in last year } \\
\text { No } \\
\text { No of wheezing episodes } \\
\quad 1-3 \\
4-12 \\
>12 \\
\text { Woken by wheeze } \\
\text { Nil } \\
<1 \text { Per week } \\
>1 \text { Per week } \\
\text { Limitation of speech during } \\
\text { wheezing attack }\end{array}$} & 723 & 316 & 407 & 430 & 292 & 594 & 75 & 36 & 456 & 95 & 154 & 27 & 66 & 112 & 194 \\
\hline & $\begin{array}{r}77 \cdot 8 \\
16.5 \\
5 \cdot 6\end{array}$ & $\begin{array}{r}76 \cdot 8 \\
18 \cdot 8 \\
4 \cdot 4\end{array}$ & $\begin{array}{r}78 \cdot 6 \\
14 \cdot 8 \\
6 \cdot 6\end{array}$ & $\begin{array}{r}76 \cdot 8 \\
16 \cdot 2 \\
7 \cdot 0\end{array}$ & $\begin{array}{r}79 \cdot 3 \\
17 \cdot 0 \\
3 \cdot 6\end{array}$ & $\begin{array}{r}78 \cdot 5 \\
15 \cdot 8 \\
5 \cdot 7\end{array}$ & $\begin{array}{r}82.4 \\
16.2 \\
1.5\end{array}$ & $\begin{array}{l}62 \cdot 9 \\
25 \cdot 7 \\
11 \cdot 4\end{array}$ & $\begin{array}{r}77 \cdot 5 \\
16 \cdot 1 \\
6.4\end{array}$ & $\begin{array}{r}79 \cdot 3 \\
19 \cdot 6 \\
1 \cdot 1\end{array}$ & $\begin{array}{r}77 \cdot 4 \\
17 \cdot 1 \\
5 \cdot 5\end{array}$ & $\begin{array}{r}75 \cdot 0 \\
20 \cdot 8 \\
4 \cdot 2\end{array}$ & $\begin{array}{r}72 \cdot 9 \\
25 \cdot 4 \\
1 \cdot 7\end{array}$ & $\begin{array}{r}76 \cdot 1 \\
15 \cdot 6 \\
8 \cdot 3\end{array}$ & $\begin{array}{r}81 \cdot 1 \\
14 \cdot 6 \\
4 \cdot 3\end{array}$ \\
\hline & & & & & & & & & & & & & & & \\
\hline & $\begin{array}{l}58.9 \\
29.9 \\
11 \cdot 2\end{array}$ & $\begin{array}{l}59 \cdot 2 \\
30 \cdot 4 \\
10 \cdot 4\end{array}$ & $\begin{array}{l}58 \cdot 7 \\
29.5 \\
11.8\end{array}$ & $\begin{array}{l}61 \cdot 2 \\
26 \cdot 7 \\
12 \cdot 1\end{array}$ & $\begin{array}{r}55 \cdot 5 \\
34 \cdot 6 \\
9.9\end{array}$ & $\begin{array}{r}61 \cdot 8 \\
29 \cdot 1 \\
9 \cdot 1\end{array}$ & $\begin{array}{l}48 \cdot 0 \\
36 \cdot 0 \\
16 \cdot 0\end{array}$ & $\begin{array}{l}36 \cdot 1 \\
30 \cdot 6 \\
33 \cdot 3\end{array}$ & $\begin{array}{l}60 \cdot 3 \\
32 \cdot 0 \\
12 \cdot 1\end{array}$ & $\begin{array}{r}70 \cdot 5 \\
20 \cdot 0 \\
9 \cdot 5\end{array}$ & $\begin{array}{r}61 \cdot 7 \\
29 \cdot 2 \\
9 \cdot 1\end{array}$ & $\begin{array}{l}51.9 \\
25.9 \\
22.2\end{array}$ & $\begin{array}{r}54 \cdot 5 \\
36 \cdot 4 \\
9 \cdot 1\end{array}$ & $\begin{array}{l}55 \cdot 4 \\
31 \cdot 3 \\
13 \cdot 4\end{array}$ & $\begin{array}{r}60 \cdot 3 \\
32 \cdot 5 \\
7 \cdot 2\end{array}$ \\
\hline & & & & & & & & & & & & & & & \\
\hline & $17 \cdot 3$ & $9 \cdot 2$ & $23 \cdot 6$ & $19 \cdot 1$ & $14 \cdot 7$ & $14 \cdot 5$ & $36 \cdot 0$ & $27 \cdot 8$ & $20 \cdot 2$ & $12 \cdot 6$ & $11 \cdot 7$ & $18 \cdot 5$ & $21 \cdot 2$ & $14 \cdot 3$ & $7 \cdot 2$ \\
\hline \multirow{2}{*}{$\begin{array}{l}\text { Rhinitis in last year } \\
\text { No } \\
\text { Interfere with daily activity } \\
\text { Not at all } \\
\text { Little } \\
\text { Moderate } \\
\text { A lot }\end{array}$} & 2258 & 535 & 1723 & 1323 & 932 & 1894 & 236 & 75 & 1623 & 248 & 339 & 58 & 246 & 318 & 379 \\
\hline & $\begin{array}{r}37 \cdot 3 \\
49 \cdot 0 \\
10 \cdot 4 \\
3 \cdot 3\end{array}$ & $\begin{array}{r}42.4 \\
44.3 \\
11.8 \\
1.5\end{array}$ & $\begin{array}{r}35.8 \\
50.5 \\
9.9 \\
3.8\end{array}$ & $\begin{array}{r}36 \cdot 9 \\
48 \cdot 9 \\
10 \cdot 7 \\
3.5\end{array}$ & $\begin{array}{r}37 \cdot 9 \\
49 \cdot 2 \\
9.9 \\
3.0\end{array}$ & $\begin{array}{r}38 \cdot 7 \\
49 \cdot 0 \\
9 \cdot 5 \\
2 \cdot 8\end{array}$ & $\begin{array}{r}30 \cdot 1 \\
52.5 \\
11.9 \\
5.5\end{array}$ & $\begin{array}{r}36.0 \\
40.0 \\
14.7 \\
9.3\end{array}$ & $\begin{array}{r}35.7 \\
50.1 \\
10.7 \\
3.5\end{array}$ & $\begin{array}{r}40 \cdot 7 \\
47 \cdot 2 \\
9 \cdot 7 \\
2 \cdot 4\end{array}$ & $\begin{array}{r}42 \cdot 5 \\
44 \cdot 8 \\
9 \cdot 7 \\
3 \cdot 0\end{array}$ & $\begin{array}{r}36 \cdot 2 \\
46.6 \\
15.5 \\
1.7\end{array}$ & $\begin{array}{r}31 \cdot 3 \\
53 \cdot 7 \\
12 \cdot 2 \\
2 \cdot 8\end{array}$ & $\begin{array}{r}36 \cdot 2 \\
47 \cdot 8 \\
12 \cdot 9 \\
3 \cdot 1\end{array}$ & $\begin{array}{r}40 \cdot 1 \\
45 \cdot 4 \\
11.9 \\
2 \cdot 6\end{array}$ \\
\hline \multirow{3}{*}{$\begin{array}{l}\text { Rashes in last year } \\
\text { No } \\
\text { Persistent rash without } \\
\text { clearing } \\
\text { Kept awake by rash } \\
\text { Never } \\
<1 \text { Per week } \\
>1 \text { Per week }\end{array}$} & 452 & 58 & 394 & 248 & 202 & 347 & 68 & 22 & 361 & 36 & 46 & 19 & 47 & 61 & 38 \\
\hline & $42 \cdot 3$ & $46 \cdot 6$ & $41 \cdot 6$ & $42 \cdot 7$ & $41 \cdot 6$ & $41 \cdot 5$ & $47 \cdot 1$ & $50 \cdot 0$ & $42 \cdot 1$ & $44 \cdot 4$ & $39 \cdot 1$ & $47 \cdot 4$ & 34.0 & $39 \cdot 3$ & $42 \cdot 1$ \\
\hline & $\begin{array}{l}58 \cdot 4 \\
30 \cdot 3 \\
11 \cdot 3\end{array}$ & $\begin{array}{l}53 \cdot 4 \\
36 \cdot 2 \\
10 \cdot 3\end{array}$ & $\begin{array}{l}59 \cdot 1 \\
29 \cdot 4 \\
11 \cdot 5\end{array}$ & $\begin{array}{r}64 \cdot 5 \\
26 \cdot 6 \\
8 \cdot 9\end{array}$ & $\begin{array}{l}51 \cdot 0 \\
35 \cdot 1 \\
13.9\end{array}$ & $\begin{array}{l}61.4 \\
26.8 \\
11.8\end{array}$ & $\begin{array}{l}48 \cdot 5 \\
41 \cdot 2 \\
10 \cdot 3\end{array}$ & $\begin{array}{l}54.5 \\
31.8 \\
13.6\end{array}$ & $\begin{array}{l}54 \cdot 8 \\
33.5 \\
11.6\end{array}$ & $\begin{array}{l}72 \cdot 2 \\
16 \cdot 7 \\
11 \cdot 1\end{array}$ & $\begin{array}{r}71 \cdot 7 \\
19 \cdot 6 \\
8 \cdot 7\end{array}$ & $\begin{array}{l}31.6 \\
57.9 \\
10.5\end{array}$ & $\begin{array}{r}70 \cdot 2 \\
25 \cdot 5 \\
4 \cdot 3\end{array}$ & $\begin{array}{l}59 \cdot 0 \\
27 \cdot 9 \\
13 \cdot 1\end{array}$ & $\begin{array}{r}81 \cdot 6 \\
18 \cdot 4 \\
0.0\end{array}$ \\
\hline
\end{tabular}

${ }^{\star}$ Condo $=$ condominium.

Eczema was the least commonly reported allergic disorder with $12 \cdot 0 \%(578 / 4803)$ of the study population reporting ever having a chronic rash, and $9.4 \%(452 / 4803)$ reporting current symptoms. This was even lower $(6.9 \%$, 330/4803) when considering only chronic rash with a typical eczema distribution (table 2). As with hayfever, we noted a similar lack of understanding. More than half $(2580 / 4803,53 \cdot 7 \%)$ were not aware of the diagnosis of eczema.

\section{SEVERITY AND CHRONICITY}

For respondents with current symptoms of asthma, rhinitis, or eczema, we assessed severity and chronicity by the number of wheezing episodes, severity of each attack, and interference of these symptoms with daily activities. Using these indicators, we observed that the older age group (12-15 years), males, Indians, Malays, and children in lower socioeconomic groups tended to have more severe atopic disease (table 3) (see below for statistical analysis). An exception was that females tended to have more severe eczema.

MULTIPLE LOGISTIC REGRESSION ANALYSIS

To evaluate the effects of each variable (age, sex, race, and socioeconomic status) on the prevalence and severity of these allergic disorders, we carried out multivariate analysis. This showed that the cumulative prevalence of wheezing was higher in the 6-7 year age group, male sex, and higher socioeconomic group (either by type of housing, or family income or both) (table 4). In contrast, Malay and Indian race was associated with more frequent and severe wheezing attacks. As expected, a positive response to wheezing was strongly associated with the presence of rhinitis or eczema (adjusted odds ratio $=2 \cdot 36$, $95 \%$ confidence interval: 2.04 to $2 \cdot 72$ ) $(\mathrm{p}<0 \cdot 001)$.
The older age group (12-15 years) and male sex had higher prevalence of rhinitis (table 4). The effect of race and socioeconomic status on rhinitis was less marked than on asthma. Eczema was not highly associated with any of the demographic data tested (table 4).

\section{Discussion}

Although the data obtained were not substantiated by procedures such as skin prick testing and exercise challenge, previous work in an English speaking population has found the ISAAC written questionnaire reasonably sensitive and specific for bronchial hyperresponsiveness. ${ }^{19}$ Most of our survey was conducted in English, with only 312 (5\%) children of non-English speaking parents who used Mandarin and Malay translations.

When our data were compared with those of two previous local surveys, there appeared to be a distinct increase in the cumulative prevalence of asthma over the last 27 years. The reported cumulative prevalence of asthma was $5.5 \%$ in $1967,,^{13} 13 \cdot 7 \%$ in $1987,,^{14}$ and $20.0 \%$ in this survey. Although confounding factors such as differences in survey methods, and a possible increase in awareness of asthma diagnosis have to be considered, this trend is in accordance with those in developed countries, ${ }^{1321}$ and parallels the rapid urbanisation of the city state of Singapore.

Despite rising local asthma prevalence figures, it was also noted that the cumulative and current prevalences of wheezing in the $12-15$ year olds $(18.6 \%$ and $9.9 \%$, respectively) were lower than in the West. Identical ISAAC surveys conducted recently on 12-15 year olds in Germany (Bochum), England (West Sussex), New Zealand (Wellington), and Australia (Adelaide and Sydney) reported cumulative and current prevalence of wheezing ranging from $33 \%$ to $45 \%$, and $20 \%$ to $30 \%$, respectively. ${ }^{16}$ 
Table 4 Effects of demographic, socioeconomic, and atopic status on the reported symptoms and diagnosis of asthma, rhinitis, and eczema (adjusted odds ratio ( $95 \%$ confidence interval))

\begin{tabular}{|c|c|c|c|c|c|c|}
\hline Symptoms & Age group ${ }^{\mathrm{a}}$ & $S e x^{a}$ & $R a c e^{\mathrm{a}}$ & Housing ${ }^{\mathrm{a}}$ & Income $e^{\mathrm{a}}$ & (atopy $y^{\mathrm{a}}$ \\
\hline \multicolumn{7}{|l|}{ Responses for asthma } \\
\hline & $\begin{array}{l}1 \cdot 08^{\star \star \star \star} \\
(1 \cdot 04-1 \cdot 13)\end{array}$ & $\begin{array}{l}0.93^{\star \star \star} \\
(0.89-0.97)\end{array}$ & NS & & $\begin{array}{l}>\$ K, 1 \cdot 12^{\star} \\
(1 \cdot 02-1 \cdot 24)\end{array}$ & $\begin{array}{l}2 \cdot 10 \ddagger \\
(1 \cdot 78-2 \cdot 48)\end{array}$ \\
\hline Wheeze, ever ${ }^{b}$ & $\begin{array}{l}0.96^{\star} \\
\quad(0.91-0.99)\end{array}$ & $\begin{array}{l}0.93 \ddagger \\
\quad(0.89-0.97)\end{array}$ & NS & $\begin{array}{l}\text { Condo, } 1 \cdot 10^{\star} \\
(1 \cdot 01-1 \cdot 21) ; \\
\text { Landed, } 1 \cdot 11^{\star} \\
(1 \cdot 02-1 \cdot 20)\end{array}$ & $\begin{array}{r}>\$ 4 \mathrm{~K}, 1 \cdot 21 \ddagger \\
\quad(1 \cdot 09-1 \cdot 35)\end{array}$ & $\begin{array}{l}2 \cdot 36 \ddagger \\
(2 \cdot 04-2 \cdot 72)\end{array}$ \\
\hline $\begin{array}{l}\text { Woken by } \\
\text { wheezing } \\
\text { last year }\end{array}$ & NS & NS & $\begin{array}{c}\text { Malay, } 1 \cdot 16^{\star} \\
(1 \cdot 01-1 \cdot 37) ; \\
\text { Indian, } 1 \cdot 58 \ddagger \\
(1 \cdot 10-2 \cdot 28)\end{array}$ & NS & NS & $\begin{array}{l}1 \cdot 36^{\star} \\
(1.02-1 \cdot 79)\end{array}$ \\
\hline $\begin{array}{l}\text { Wheezing } \\
\text { attack which } \\
\text { limits speech }\end{array}$ & $\begin{array}{l}1 \cdot 19^{\star} \\
(1 \cdot 02-1 \cdot 38)\end{array}$ & NS & $\begin{array}{l}\text { Malay, } 1 \cdot 28 \ddagger \\
(1 \cdot 12-1 \cdot 46) ; \\
\text { Indian, } 1 \cdot 16^{\star} \\
(1 \cdot 01-1 \cdot 36)\end{array}$ & NS & NS & $\begin{array}{l}1.94^{\star} \\
\quad(1.05-3.59)\end{array}$ \\
\hline \multicolumn{7}{|l|}{ Responses for rhinitis } \\
\hline $\begin{array}{l}\text { Diagnosed } \\
\text { hayfever, ever }\end{array}$ & NS & NS & NS & $\begin{array}{r}\text { Condo, } 0.95^{\star} \\
(0.91-0.99)\end{array}$ & NS & $\begin{array}{l}2 \cdot 44 \ddagger \\
\quad(1.75-3 \cdot 41)\end{array}$ \\
\hline $\begin{array}{l}\text { Ever had } \\
\text { rhinitis }\end{array}$ & $\begin{array}{l}1 \cdot 67 \ddagger \\
(1 \cdot 56-1 \cdot 79)\end{array}$ & $\begin{array}{l}0.91 \dagger \\
\quad(0.86-0.97)\end{array}$ & $\begin{array}{l}\text { Indian, } 0.79 \dagger \\
(0.68-0.92)\end{array}$ & NS & $\begin{array}{c}\$ 1-2 \mathrm{~K}, 1.18 \dagger \\
(1.06-1.31) ; \\
\$ 2-4 \mathrm{~K}, 1.21 \dagger \\
(1.08-1.35) ; \\
>\$ 4 \mathrm{~K}, 1.25 \dagger \\
(1.09-1.43)\end{array}$ & $\begin{array}{l}2 \cdot 11 \ddagger \\
(1 \cdot 93-2 \cdot 30)\end{array}$ \\
\hline $\begin{array}{l}\text { Associated } \\
\text { itchy eyes }\end{array}$ & $\begin{array}{l}1 \cdot 12^{\star} \\
(1 \cdot 01-1 \cdot 24)\end{array}$ & NS & $\begin{array}{l}\text { Malay, } 1 \cdot 24^{\star} \\
(1 \cdot 03-1 \cdot 48)\end{array}$ & NS & NS & $\begin{array}{l}1 \cdot 45 \ddagger \\
\quad(1 \cdot 20-1 \cdot 75)\end{array}$ \\
\hline $\begin{array}{l}\text { Interfere with } \\
\text { daily activity }\end{array}$ & $\begin{array}{l}1 \cdot 35^{\star \star} \\
(1 \cdot 12-1 \cdot 63)\end{array}$ & NS & NS & $\begin{array}{c}\text { Landed, } 0 \cdot 74^{\star} \\
(0 \cdot 57-0 \cdot 96)\end{array}$ & NS & $\begin{array}{l}1 \cdot 33 \ddagger \\
\quad(1 \cdot 20-1 \cdot 48)\end{array}$ \\
\hline $\begin{array}{l}\text { Responses for eczema } \\
\text { Diagnosed } \\
\text { eczema, ever }\end{array}$ & $\begin{array}{l}1 \cdot 07^{\star \star} \\
(1 \cdot 02-1 \cdot 13)\end{array}$ & NS & NS & NS & $\begin{array}{r}>\$ 4 \mathrm{~K}, 1 \cdot 17^{\star} \\
\quad(1 \cdot 01-1 \cdot 36)\end{array}$ & $\begin{array}{l}4 \cdot 70 \ddagger \\
\quad(2 \cdot 84-7 \cdot 80)\end{array}$ \\
\hline $\begin{array}{l}\text { Chronic } \\
\text { rash, ever }\end{array}$ & NS & NS & $\begin{array}{l}\text { Indian, } 1 \cdot 12^{\star} \\
\quad(1 \cdot 01-1 \cdot 23)\end{array}$ & NS & NS & $\begin{array}{l}2 \cdot 83 \ddagger \\
\quad(2 \cdot 16-3 \cdot 70)\end{array}$ \\
\hline
\end{tabular}

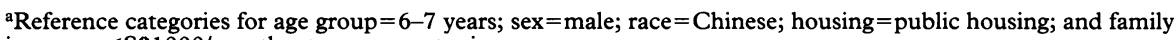

income $=<S \$ 1000 /$ month; atopy $=$ non-atopic.

${ }^{a}$ Atopy $=$ show symptoms of other atopic diseases. Symptoms of rhinitis and eczema were used to define the atopic status (atopic) in the analysis for asthma, while symptoms of asthma and eczema were used for rhinitis).

${ }^{b}$ Ever wheeze was defined as a positive response for every wheezing, or wheezing with exercise in the written questionnaire. ${ }^{\star} \mathrm{p}<0.05, \neq \mathrm{p}<0.01, \neq \mathrm{p}<0.001$.

Our figures are comparable with a recent nationwide ISAAC survey in Great Britain, which reported cumulative and current prevalence of wheezing of $23 \%$ and $15 \% .{ }^{17}$ The prevalence of diagnosed asthma was higher in our population $(20.0 \%)$ than in the British study $(13 \cdot 1 \%)$. Thus our local prevalence figures probably lie somewhere between those of the West and developing countries. The reported cumulative and current prevalence of wheezing in southern China are reported to be as low as 1.9 and $1 \cdot 1 \%{ }^{21}$ Singaporean Chinese are of southern Chinese descent, suggesting that geographical differences in wheezing and asthma prevalence may be influenced more by environment than genetics.

As expected, there was a strong association between reported asthma symptoms and symptoms of other atopic disorders $(p<0.001)$. Persistent rhinitis was found to be the most common symptom reported, with cumulative and current prevalence of $44.5 \%$ and $37.1 \%$, respectively. When confined to those with concomitant symptoms of itchy eyes, a clinical indicator of allergic rhinitis, the current prevalence was $15 \cdot 4 \%$, slightly higher than the prevalence ranges of $6-12 \%$ in other populations. ${ }^{22-24}$ The lack of seasonality of rhinitis symptoms in our population is consistent with the tropical climate and the high frequency of sensitivity to house dust mite allergens in our atopic subjects. ${ }^{25}$ Eczema is the least common allergic disorder in our population, with a current prevalence of rashes of typical distribution of $6.9 \%$, a figure comparable with reported prevalence of childhood eczema in Taiwan ${ }^{26}$ and mainland China. ${ }^{21}$
Multiple logistic regression analysis, which adjusts for confounding variables, was used to evaluate the effects of age, sex, race, and socioeconomic status on the prevalence and severity of wheezing, rhinitis, and eczema (table 4). Higher prevalence of wheezing and other atopy related symptoms was observed in the higher socioeconomic group, but the lower income group experienced more severe disease. The former observation has also been reported in studies conducted in the United Kingdom. ${ }^{27-30}$

A previous survey on adult asthma in Singapore ${ }^{31}$ showed increased prevalence in Indians and Malays compared to Chinese, but our data indicate that the prevalence is similar in all racial groups. The Indians and Malays, however, had more severe asthma than the Chinese. Although the reasons for this difference are not evident, previous work suggests that environmental factors such as smoking and rearing of pets are important. ${ }^{31}$ Another possibility might be the smaller airways inherently present in Malay and Indian children. ${ }^{32}$

This study was part of an international effort to evaluate and compare the epidemiology of asthma and allergic disease around the world. Our results suggest that atopic disorders are an increasing problem not only in the West but also in an Asian population. It appears that demographic and socioeconomic factors both play a role in influencing the prevalence and severity of these disorders. The reasons behind these differences will be evaluated with the ISAAC phase II protocol which is currently being formulated.

This study was supported by a research grant from Glaxo Wellcome (Singapore) Pte Ltd. 


\section{Appendix}

\section{Written questionnaire}

CORE QUESTIONNAIRE FOR WHEEZING AND ASTHMA*:

1. Have you ever had wheezing or whistling in your chest at any time in the past? Yes/No. If 'no', skip to question 6 .

2. Have you had wheezing or whistling in your chest in the last 12 months? Yes/No. If 'no', skip to question 6 .

3. How many attacks of wheezing have you had in the last 12 months? None, 1-3, 4-12, $>12$.

4. In the last 12 months, how often, on the average, has your sleep been disturbed due to wheezing? Never woken with wheezing, Less than one night per week, One or more nights per week.

5. In the last 12 months, has wheezing ever been severe enough to limit your speech to only one or two words at a time between breaths? Yes/No

6. Have you ever had asthma? Yes/No

7. In the last 12 months, has your chest sounded wheezy during or after excercise? Yes/No

8. In the last 12 months, have you had a dry cough associated with a cold or chest infection? Yes/No

CORE QUESTIONNAIRE FOR RHINITIS*:

1. Have you ever had a problem with sneezing, or blocked nose when you did not have a cold or flu? Yes/No. If 'no' skip to question 6.

2 . In the past 12 months, have you had a problem with sneezing, or a runny or blocked nose when you did not have a flu? Yes/No. If 'no' skip to question 6 .

3. In the past $\mathbf{1 2}$ months, has this nose problem been accompanied by itchy-watery eyes? Yes/No

4. In which of the past 12 months did this nose problem occur?

5. In the past 12 months, how much did this nose problem interfere with your activities? Not at all, A little, A moderate amount, A lot. 6. Have you ever had hayfever? Yes/No/Don't know.

CORE QUESTIONNAIRE FOR ECZEMA*:

1. Have you ever had an itchy rash that was coming and going for at least 6 months? Yes/No If 'no' skip to question 6.

2. Have you had an itchy rash at any time in the last 12 months? Yes/No. If 'no' skip to question 6.

3. Has this itchy rash at any time affected any of the following places: the folds of the elbows, behind the knees, in front of the ankles, under the buttocks, around the neck, ears or eyes? Yes/No

4. Has this rash cleared completely at any time in the last 12 months? Yes/No.

5 . In the last 12 months, how often, on average, have you been kept awake at night by this itchy rash? Never in the last 12 months, Less than one night per week, One or more nights per week.
6. Have you ever had eczema? Yes/No/Don't know.

*These questions were directed at 12-15 year olds who self completed the questionnaire; questions were modified for 6-7 years olds whose parents completed the questions.

1 Ninan TK, Russell G. Respiratory symptoms and atopy in Aberdeen schoolchildren: evidence from two surveys 25 years part. BMF 1992; 304: 873-5

2 Robertson CF, Heycock E, Bishop J, Nolan T, Olinsky A, Phelan PD. Prevalence of asthma in Melbourne schoolchildren: changes over 26 years. BMf 1991; 302: 11 16-8. children: changes over 26 years. BMf 1991; 302: 1116-8.
3 Burr ML, Butland BK, King S, Vaughn-Williams E. Changes in asthma prevalence: two surveys 15 years apart. Arch Dis Child 1989; 64: 1452-6.

4 Weiss KB, Gergen PJ, Hodgson TA. An economic evaluation of asthma in the United States. N Engl f Med 1992; 326: 862-6.

5 Sullivan SD, Weiss KB. Assessing cost effectiveness in asthma care: building an economic model to study the impact of alternative intervention strategies. Allergy 1993; 48 (suppl 17): 146-52; discussion 162-3.

6 Sears MR, Burrows B, Flannery EM, Herbison GP, Hewitt CJ, Holdaway MD. Relation between airway responsiveness and serum IgE in children with asthma and apparently normal children. N Engl f Med 1991; 325: and apparent $1067-71$.

7 Holt PG, McMenamin C, Nelson D. Primary sensitisation to inhalant allergens during infancy. Pediatr Allergy Immunol 1990; 1: 3-13.

8 Egbuonu L, Starfield BS. Child health social status. Pediatrics 1982; 69: 550-7.

9 Leung R, Tseng RYM. Allergic diseases in Hongkong schoolchildren. Hongkong Practitioner 1993; 15: 2409-20.

10 Zhong NS, Chen RC, O-yang M, et al. Bronchial hyperresponsiveness in young students of southern China: relation to respiratory symptoms, diagnosed asthma, and risk factors. Thorax 1991; 45: 860-5.

11 Omar AH. Respiratory symptoms and asthma in primary school children in Kuala Lumpur. Acta Paediatr fpn 1990, 32: 183-7.

12 Hsieh KH, Shen J. Prevalence of childhood asthma in Taipei, Taiwan and other Asian Pacific countries. $\mathcal{F}$ Asthma 1988; 25: 73-82.

13 Chong TM. Pattern of bronchial asthma in Singapore. Singapore Med f 1972; 13: 154-60.

14 Teo J, Quak SH, Low PS, Wong HB. Childhood asthma in Singapore - changing trends. In: Proceedings of the $22 n d$ Singapore Malaysia Congress of Medicine 1988: 180.

15 ISAAC Co-ordinating Committee. Manual for the International Study of Asthma and Allergies in Childhood (ISAAC). Bochum and Auckland: ISAAC Coordinating Committee, 1992.

16 Pearce N, Weiland S, Keil U, Langridge P, Anderson HR, Strachan D. Self-reported prevalence of asthma symptoms in children in Australia, England, Germany and New Zealand: an international comparison using the ISAAC protocol. Eur Respir f 1993; 6: 1455-61

17 Strachan DP, Anderson HR, Limb ES, O'Neil AO, Wells N. A national survey of asthma prevalence, severity and treatment in Great Britain. Arch Dis Child 1994; 70: 174-8.

18 Census of Population Office, Department of Statistics, Singapore. Singapore census of population in 1990: houseSingapore. Singapore census of population in 1990: house-
holds and housing, statistical release 2. Singapore National holds and housing, stat
Printers Ltd, 1992.

19 Shaw RA, Crane J, Pearce N, et al. Comparison of a video questionnaire with the IUATLD written questionnaire for measuring asthma prevalence. Clin Exp Allergy 1992; 22: 561-8.

20 Burney PG, Chinn S, Rona RJ. Has the prevalence of asthma increased in children? Evidence from the national study of health and growth 1973-86. BMF 1990; 300: 1306-10.

21 Leung R, Jenkins $M$. Asthma , allergy and atopy in southern Chinese school students. Clin Exp Allergy 1994; 24: 353-8.

22 Poysa L, Korppi M, Remes K, Juntunen-Backman K. Asthma, allergic rhinitis and atopic dermatitis in Finnish children and adolescents. Allergy 1991; 46: 161-5.

23 Weeke ER. Epidemiology of allergic diseases in children Rhinology 1992; 13 (suppl): 5-12.

24 Fleming DM, Crombie DL. Prevalence of asthma and hayfever in England and Wales. $B M \mathcal{F} 1987 ; 294: 279-83$.

25 Lee BW, Teo J, Vellayappan K. Role of atopy in childhood asthma. $\mathcal{F}$ Singapore Paediatr Soc 1989; 31: 53-9.

26 Hsieh KH, Tsai YT. Increasing prevalence of childhood allergic disease in Taipei, Taiwan, and the outcome. Proceedings of the 14th International Congress of Allergy and Clinical Immunology, Kyoto, Japan, 1991.

27 Anderson HR, Bland JM, Patel S, Peckham C. The natura history of asthma in childhood. $\mathcal{f}$ Epidemiol Community Health 1986; 40: 231-6.

28 Hamman RF, Halil T, Holland WW. Asthma in schoolchildren. Br f Prev Soc Med 1975; 29: 228-38.

29 Kaplan BA, Mascie-Taylor CGN. Biosocial factors in the epidemiology of childhood asthma in a British national epidemiology of childhood asthma in a British national sample. F Epidemiol Community Health 1985; 39: 152-6. hood. $\mathcal{F}$ Epidemiol Community Health 1978; 32: 79-85.

$31 \mathrm{Ng}$ TP, Hui KP, Tan WC. Prevalence of asthma and risk factors among Chinese, Malay, and Indian adults in

32 Connett GJ, Quak SH, Teo J, Wong ML, Lee BW. Lung function reference values in Singapore children aged 6-18 years. Thorax 1994; 49: 901-5. 